\title{
LiaRS-dependent gene expression is embedded in transition state regulation in Bacillus subtilis
}

Correspondence
Thorsten Mascher
tmasche@gwdg.de

Received 9 February 2007

Revised 5 April 2007

Accepted 27 April 2007

\author{
Sina Jordan, ${ }^{1}$ Eva Rietkötter, ${ }^{1}$ Mark A. Strauch, ${ }^{2}$ Falk Kalamorz, ${ }^{1}$ \\ Bronwyn G. Butcher, ${ }^{3}$ John D. Helmann ${ }^{3}$ and Thorsten Mascher ${ }^{1}$ \\ 1Department of General Microbiology, Georg-August-University, 37077 Göttingen, Germany \\ ${ }^{2}$ Department of Biomedical Sciences, University of Maryland Dental School, Baltimore, \\ MD 21201, USA \\ ${ }^{3}$ Department of Microbiology, Cornell University, Ithaca, NY 14853-8101, USA
}

\section{INTRODUCTION}

The envelope is a crucial structure of the bacterial cell and the target of many antibiotics (Silver, 2003, 2006; Walsh, 2003). Its integrity is closely monitored to detect and counteract threats before their action can lead to irreversible damages. The LiaRS two-component system (TCS) is part of the complex regulatory network that orchestrates the cell-envelope stress response in Bacillus subtilis (Mascher et al., 2003). It responds strongly to the external presence of cell wall antibiotics that interfere with the lipid II cycle, such as bacitracin, ramoplanin, vancomycin or cationic antimicrobial peptides (Mascher et al., 2004; Pietiäinen et al., 2005). It is also induced by alkaline shock, detergents, ethanol, phenol, organic solvents and secretion stress, albeit to a lesser extent (Hyyryläinen et al., 2005; Mascher et al., 2004; Petersohn et al., 2001; Pietiäinen et al., 2005; Tam le et al., 2006; Wiegert et al., 2001).

The LiaRS TCS is functionally and genetically linked to a third protein, LiaF, which acts as a strong inhibitor of LiaR-dependent gene expression (Jordan et al., 2006). The LiaRS-LiaF three-component system is conserved by sequence and genomic context in Gram-positive bacteria with a low G $+\mathrm{C}$ content (Firmicutes) (Jordan et al., 2006;

Abbreviations: LFH-PCR, long flanking homology PCR; MLS, macrolidelincosamide-streptogramin; TCS, two-component system.
Mascher, 2006), and LiaRS-homologous TCSs are also involved in responding to cell envelope stress in Bacillus licheniformis, Streptococcus pneumoniae and Staphylococcus aureus (Haas et al., 2005; Kuroda et al., 2003; Wecke et al., 2006). It is interesting to note that membrane-anchored inhibitory proteins, working together with a classical TCS, have also been described for the cell-wall-related, essential TCS YycFG; the YycH and YycI proteins both inhibit the YycG kinase (Szurmant et al., 2007).

In $B$. subtilis, only two promoters are known to be regulated by the LiaRS TCS: the liaI promoter $\left(\mathrm{P}_{\text {liaI }}\right)$ and the $y h c Y$ promoter (Jordan et al., 2006), with $\mathrm{P}_{\text {liaI }}$ being the primary target. In contrast to $\mathrm{P}_{\text {lial }}$, a LiaR-dependent $\mathrm{P}_{y h c Y}$ activity was only observed in a liaF mutant, i.e. in the absence of the LiaRS-inhibitor protein (Jordan et al., 2006; Mascher et al., 2004). $\mathrm{P}_{\text {liaI }}$ is tightly regulated: in the absence of a stimulus, it is virtually switched off, while addition of bacitracin results in about 200-fold induction (Mascher et al., 2003, 2004).

The lia locus consists of six genes, liaIH-liaGFSR. A basal expression level of the last four genes, liaGFSR, encoding the three-component system (liaFSR) and a putative membrane-anchored hypothetical protein (liaG), is ensured by a weak constitutive promoter upstream of liaG. In contrast, expression of the liaIH operon from $\mathrm{P}_{\text {liaI }}$ is completely LiaR-dependent (Jordan et al., 2006). LiaI is a small hydrophobic protein of unknown function with two 
putative transmembrane helices. $\mathrm{LiaH}$ is a member of the phage-shock protein family (see below). While the strong induction of liaIH (and to a lesser degree also liaGFSR) by cell envelope stress is well documented (see above), mutational analysis of the lia locus has so far failed to identify strong phenotypes associated with these genes. Deletion of lia genes did not alter the sensitivity of the corresponding mutants to the known inducers of the Lia system. Moreover, none of the complex differentiation processes of B. subtilis (i.e. sporulation, competence for genetic transformation, motility and pellicle and fruiting body formation) was affected in lia mutants. So far, the only phenotype that could be linked to the Lia system is delayed spore germination in a liaH mutant (D. Hoyer \& T. Mascher, unpublished). Moreover, LiaH seems to negatively affect the expression of the $y h c Y Z$ operon by a currently unknown mechanism. It is weakly inducible by bacitracin only in a liaH mutant, but not in the wild-type (Mascher et al., 2003).

While the physiological role of LiaI and LiaH remains obscure, we noted some similarities between LiaH and phage-shock protein A (PspA) of Escherichia coli. The latter is induced by various stress conditions such as filamentous phage infection (hence the name), heat shock, osmotic shock and exposure to organic solvents and proton ionophores as well as prolonged incubation under alkaline conditions (Brissette et al., 1990; Kobayashi et al., 1998; Weiner \& Model, 1994). This inducer spectrum shows some overlap with the known inducers of liaIH expression, which include organic solvents and alkaline shock (Mascher et al., 2004; Wiegert et al., 2001). PspA exhibits a dual function that is linked to two different cellular locations (Brissette et al., 1990; Kleerebezem \& Tommassen, 1993). Peripherally bound to the inner surface of the cytoplasmic membrane (through protein-protein interactions), PspA is somehow involved in the maintenance of cell membrane integrity (Darwin, 2005; Kleerebezem et al., 1996). As a free cytosolic protein it inhibits the AAA + enhancer protein PspF, also through protein-protein interactions (Adams et al., 2003; Bordes et al., 2003; Dworkin et al., 2000). Based on the strong induction of liaH by cell envelope stress and its cotranscription with liaI, which encodes a small putative membrane protein, we speculate that LiaI serves as a membrane anchor for LiaH, thereby facilitating an activity that might somehow be linked to envelope integrity.

Here, we investigated the intrinsic activity and regulation of $\mathrm{P}_{\text {lial }}$ in the absence of exogenous stimuli. We show that $\mathrm{P}_{\text {liaI }}$ is induced at the onset of stationary phase. This time point in the B. subtilis life cycle is characterized by the initiation of a complex regulatory cascade that allows the bacterium to adapt to worsening living conditions, which can ultimately lead to the formation of dormant endospores (Errington, 2003; Msadek, 1999; Phillips \& Strauch, 2002). We demonstrate that $P_{l i a I}$ is directly repressed by binding of the transition-state regulator AbrB within the promoter sequence, thereby acting as a roadblock to prevent premature $\mathrm{P}_{\text {liaI }}$ activity during exponential growth. AbrB repression is released during the transition state by Spo0A, the master regulator of sporulation, and $\mathrm{P}_{\text {liaI }}$ is induced by an unidentified endogenous stimulus, resulting in the expression of the liaIH operon. While AbrB binding is sufficient to inhibit the endogenous growth-dependent induction of $\mathrm{P}_{\text {lial }}$, it can be bypassed completely by exogenous induction with cell wall antibiotics.

\section{METHODS}

Bacterial strains and growth conditions. B. subtilis was routinely grown in LB medium at $37{ }^{\circ} \mathrm{C}$ with aeration. All strains used in this study are derivatives of the wild-type strain W168 and are listed in Table 1. Kanamycin $\left(10 \mu \mathrm{g} \mathrm{ml}^{-1}\right)$, chloramphenicol $\left(5 \mu \mathrm{g} \mathrm{ml}^{-1}\right)$, spectinomycin $\left(100 \mu \mathrm{g} \mathrm{ml}^{-1}\right)$, tetracycline $\left(10 \mu \mathrm{g} \mathrm{ml}^{-1}\right)$, and erythromycin $\left(1 \mu \mathrm{g} \mathrm{ml}^{-1}\right)$ plus lincomycin $\left(25 \mu \mathrm{g} \mathrm{ml}^{-1}\right)$ for macrolidelincosamide-streptogramin (MLS) resistance were used for the selection of the B. subtilis mutants used in this study. Transformation was carried out as described previously (Harwood \& Cutting, 1990).

Allelic replacement mutagenesis using long-flanking-homology (LFH)-PCR. This technique is derived from a published procedure (Wach, 1996) and was performed as described previously (Mascher et al., 2003). In brief: resistance cassettes were amplified from a suitable vector as template (Guerout-Fleury et al., 1995; Youngman, 1990). Two primer pairs were designed to amplify $\sim 1000$ bp DNA fragments flanking the region to be deleted at its $5^{\prime}$ - and $3^{\prime}$-ends. The resulting fragments are here called 'up' and 'do' fragments. The 3 ' end of the up-fragment and the $5^{\prime}$-end of the do-fragment extended into the gene(s) to be deleted in a way that all expression signals of genes up- and downstream of the targeted genes remained intact. Extensions of $\sim 25$ nucleotides were added to the 5 ' -end of the 'upreverse' and the 'do-forward' primers that were complementary (opposite strand and inverted sequence) to the $5^{\prime}$ - and $3^{\prime}$-ends of the amplified resistance cassette. All fragments obtained were purified using the PCR-purification kit from Qiagen. In a second PCR 100$150 \mathrm{ng}$ of the up- and do-fragments and 250-300 ng of the resistance cassette were used together with the specific up-forward and doreverse primers at standard concentrations. In this reaction the three fragments were joined by the 25 nucleotide overlapping complementary ends and simultaneously amplified by normal primer annealing. The PCR products were directly used to transform B. subtilis. Transformants were screened by colony-PCR, using the up-forward primer with a reverse-check primer annealing inside the resistance cassette (Table 2). The integrity of the regions flanking the integrated resistance cassettes was verified by sequencing PCR products of $\sim 1000$ bp amplified from chromosomal DNA of the resulting mutants. Sequencing was performed in-house by the GenoMIK centre. All PCRs were done in a total volume of $50 \mu \mathrm{l}(10 \mu \mathrm{l}$ for colony PCR) using the HotStar DNA-Polymerase Mastermix (Qiagen) or TripleMaster Polymerase Mix (Eppendorf) according to the manufacturers' procedures. The constructed strains are listed in Table 1. The primers used are listed in Table 2.

Construction of a clean liaS deletion mutant. To ensure 'normal' (i.e. wild-type) expression levels of liaR, we constructed a clean deletion of lias using the vector pMAD (Arnaud et al., 2004). The genomic regions $\sim 1 \mathrm{~kb}$ upstream and downstream of liaS were amplified using primers listed in Table 2 [fragments liaS(clean) up, and liaS(clean) down], thereby introducing a 26 bp extension to the 3 '-end of the up-fragment, which is complementary to the $5^{\prime}$-end of the down-fragment. The two fragments were fused in a second, 
Table 1. Strains used in this study

\begin{tabular}{|c|c|c|}
\hline Strain & Relevant genotype ${ }^{\star}$ & Source, reference, construction $\dagger$ \\
\hline W168 & Wild-type strain, $\operatorname{trp} C 2$ & Lab stock \\
\hline BFS2470 & liaI::pMUTIN & Mascher et al. (2003) \\
\hline НВ0933 & liaR:: $\mathrm{kan}^{\mathrm{R}}$ & Mascher et al. (2003) \\
\hline TMB011 & liaI::pMUTIN, liaR:: $\operatorname{kan}^{\mathrm{R}}$ & Chrom. DNA (HB0933) $\rightarrow$ BFS 2470 \\
\hline TMB079 & $\sin R:: \operatorname{spec}^{\mathrm{R}}$ & LFH-PCR $\rightarrow \mathrm{W} 168$ \\
\hline TMB080 & $\operatorname{aprE}:: \operatorname{kan}^{\mathrm{R}}$ & LFH-PCR $\rightarrow$ W168 \\
\hline TMB081 & scoC: : tet $^{\mathrm{R}}$ & LFH-PCR $\rightarrow$ W168 \\
\hline TMB082 & $a b r B:: \operatorname{kan}^{\mathrm{R}}$ & LFH-PCR $\rightarrow$ W168 \\
\hline TMB083 & salA : : et $^{\mathrm{R}}$ & LFH-PCR $\rightarrow$ W168 \\
\hline TMB084 & liaI::pMUTIN, sinR:: $\operatorname{spec}^{\mathrm{R}}$ & Chrom. DNA (TMB079) $\rightarrow$ BFS2470 \\
\hline TMB085 & liaI::pMUTIN, aprE:: $\operatorname{kan}^{\mathrm{R}}$ & Chrom. DNA (TMB080) $\rightarrow$ BFS2470 \\
\hline TMB086 & liaI::pMUTIN, scoC:: $\operatorname{kan}^{\mathrm{R}}$ & Chrom. DNA (TMB081) $\rightarrow$ BFS2470 \\
\hline TMB087 & liaI::pMUTIN, abrB:: $\operatorname{kan}^{\mathrm{R}}$ & Chrom. DNA (TMB082) $\rightarrow$ BFS2470 \\
\hline TMB088 & liaI:: pMUTIN, salA:: tet ${ }^{\mathrm{R}}$ & Chrom. DNA (TMB083) $\rightarrow$ BFS2470 \\
\hline TMB117 & liaI::pMUTIN, $\operatorname{deg} U:: \operatorname{kan}^{\mathrm{R}}$ & Chrom. DNA (TMB124) $\rightarrow$ BFS2470 \\
\hline TMB118 & liaI::pMUTIN, spo0A:: tet $^{\mathrm{R}}$ & Chrom. DNA (TMB205) $\rightarrow$ BFS2470 \\
\hline TMB124 & $\operatorname{deg} U:: \operatorname{kan}^{\mathrm{R}}$ & LFH-PCR $\rightarrow$ W168 \\
\hline TMB205 & spo0A: : tet $^{\mathrm{R}}$ & LFH-PCR $\rightarrow$ W168 \\
\hline TMB209 & liaI::pMUTIN, abrB:: $\operatorname{kan}^{\mathrm{R}}$, spo0A:: tet ${ }^{\mathrm{R}}$ & Chrom. DNA (TMB082) $\rightarrow$ TMB118 \\
\hline TMB213 & $\Delta l i a S$ & pMAD-based clean deletion \\
\hline TMB215 & $\Delta$ lias, liaI: : pMUTIN & Chrom. DNA (BFS2470) $\rightarrow$ TMB213 \\
\hline TMB330 & $\Delta l i a S$, liaI::pMUTIN, abrB:: $\operatorname{kan}^{\mathrm{R}}$ & Chrom. DNA (TMB082) $\rightarrow$ TMB215 \\
\hline
\end{tabular}

${ }^{\star}$ kan, kanamycin; spec, spectinomycin; tet, tetracycline.

$\dagger$ All deletion mutants were constructed by replacing the corresponding gene with a resistance cassette, applying the LFH-PCR strategy as described previously (Mascher et al., 2003; Wach, 1996). See Table 2 for sequences of the primers used for their construction. Subsequent strains were constructed by transformation of a recipient strain, given after the arrow, with chromosomal (chrom.) DNA from the donor strain (in parentheses).

joining, PCR, and the resulting fragment was cloned into pMAD via BamHI and EcoRI, generating pMM101. Generation of the clean deletion basically followed the established procedure (Arnaud et al., 2004). In brief: B. subtilis W168 was transformed with pMM101 and incubated at $30{ }^{\circ} \mathrm{C}$ with MLS selection on LB agar plates supplemented with X-Gal. Blue colonies were picked and incubated for $6-8 \mathrm{~h}$ at $42{ }^{\circ} \mathrm{C}$ in LB medium with MLS selection, resulting in the integration of pMM101 into the chromosome. Again, blue colonies were picked from $\mathrm{LB}(\mathrm{X}-\mathrm{Gal})$ plates and incubated for $6 \mathrm{~h}$ in $\mathrm{LB}$ medium without selection. Subsequently, the liquid culture was shifted to $30{ }^{\circ} \mathrm{C}$ for $3 \mathrm{~h}$, and the cells were then plated on $\mathrm{LB}$ (X-Gal) plates, this time without selective pressure. White colonies that had lost the plasmid were picked and checked for MLS sensitivity. Those harbouring a clean deletion of liaS ( $\sim 50 \%$ of the white clones) were identified by PCR.

Measurement of induction by $\boldsymbol{\beta}$-galactosidase assay. For timecourse experiments on $\mathrm{P}_{\text {liaI }}$ induction, the respective reporter strains (listed in Table 1) were inoculated in LB medium from a fresh midexponential pre-culture to $\mathrm{OD}_{600} \sim 0.1$ and incubated at $37{ }^{\circ} \mathrm{C}$ with aeration. Samples $(2 \mathrm{ml})$ were taken every hour and $\mathrm{OD}_{600}$ was monitored to follow growth of the cultures. The pellets were resuspended in $1 \mathrm{ml}$ working buffer $\left(60 \mathrm{mM} \mathrm{Na} \mathrm{HPO}_{4}, 40 \mathrm{mM}\right.$ $\mathrm{NaH}_{2} \mathrm{PO}_{4}, 10 \mathrm{mM} \mathrm{KCl}, 1 \mathrm{mM} \mathrm{MgSO}, 20 \mathrm{mM} \beta$-mercaptoethanol) and suitable dilutions were assayed for $\beta$-galactosidase activity, with normalization to cell density (Miller, 1972). For induction experiments, the cells were inoculated from fresh overnight cultures and grown in $\mathrm{LB}$ medium at $37{ }^{\circ} \mathrm{C}$ with aeration until they reached $\mathrm{OD}_{600} \sim 0.6$. The culture was split, adding bacitracin $\left(50 \mu \mathrm{g} \mathrm{ml}^{-1}\right.$ final concentration) to one half (induced sample) and leaving the other half untreated (uninduced control). After incubation for an additional $30 \mathrm{~min}$ at $37^{\circ} \mathrm{C}$ with aeration, $2 \mathrm{ml}$ of each culture was harvested and the cell pellets were frozen and kept at $-20{ }^{\circ} \mathrm{C}$. The pellets were resuspended in $1 \mathrm{ml}$ working buffer and assayed for $\beta$ galactosidase activity as described with normalization to cell density (Miller, 1972).

Western blotting. Total cytoplasmic proteins were prepared from $15 \mathrm{ml}$ culture per time point by using a French press. Proteins $(20 \mu \mathrm{g}$ per lane) were separated by SDS-PAGE, according to standard procedure (Sambrook \& Russell, 2001). After electrophoresis the gels were equilibrated in transfer buffer [15.2 $\mathrm{g}$ Tris; $72.1 \mathrm{~g}$ glycine; $750 \mathrm{ml}$ methanol $(100 \%)$ in a final volume of 51 with deionized water] for 30 s. A PVDF membrane was activated with methanol (100\%) and subsequently incubated in transfer buffer for $5 \mathrm{~min}$. The proteins were blotted to this membrane using a semi-dry blot apparatus. After transfer $\left(1 \mathrm{~h}\right.$ at $\left.0.8 \mathrm{~mA} \mathrm{~cm}{ }^{-2}\right)$ the membrane was incubated in blotto [ $1 \times$ TBS $(50 \mathrm{mM}$ Tris, $150 \mathrm{mM} \mathrm{NaCl}, \mathrm{pH}$ 7.6), $2.5 \%$ skim milk] overnight to prevent non-specific binding. The LiaH antibody [polyclonal rabbit antisera raised against purified $\mathrm{His}_{10}-\mathrm{LiaH}$ (F. Kalamorz \& T. Mascher, unpublished) at SEQLAB (Göttingen, Germany)] was diluted $1: 20000$ in blotto. After incubation for $3 \mathrm{~h}$, the membrane was washed three times for $30 \mathrm{~min}$ with blotto. The secondary antibody [anti rabbit IgG, coupled with alkaline phosphatase (Roche Diagnostics)] was diluted 1:100000 and the membrane was incubated for $30 \mathrm{~min}$. After three more $20 \mathrm{~min}$ washing steps, the membrane was washed with deionized water and incubated in buffer III (0.1 M Tris, $0.1 \mathrm{M} \mathrm{NaCl}$; pH 9.5) for 5 min to adjust the pH. For 
Table 2. Oligonucleotides used in this study

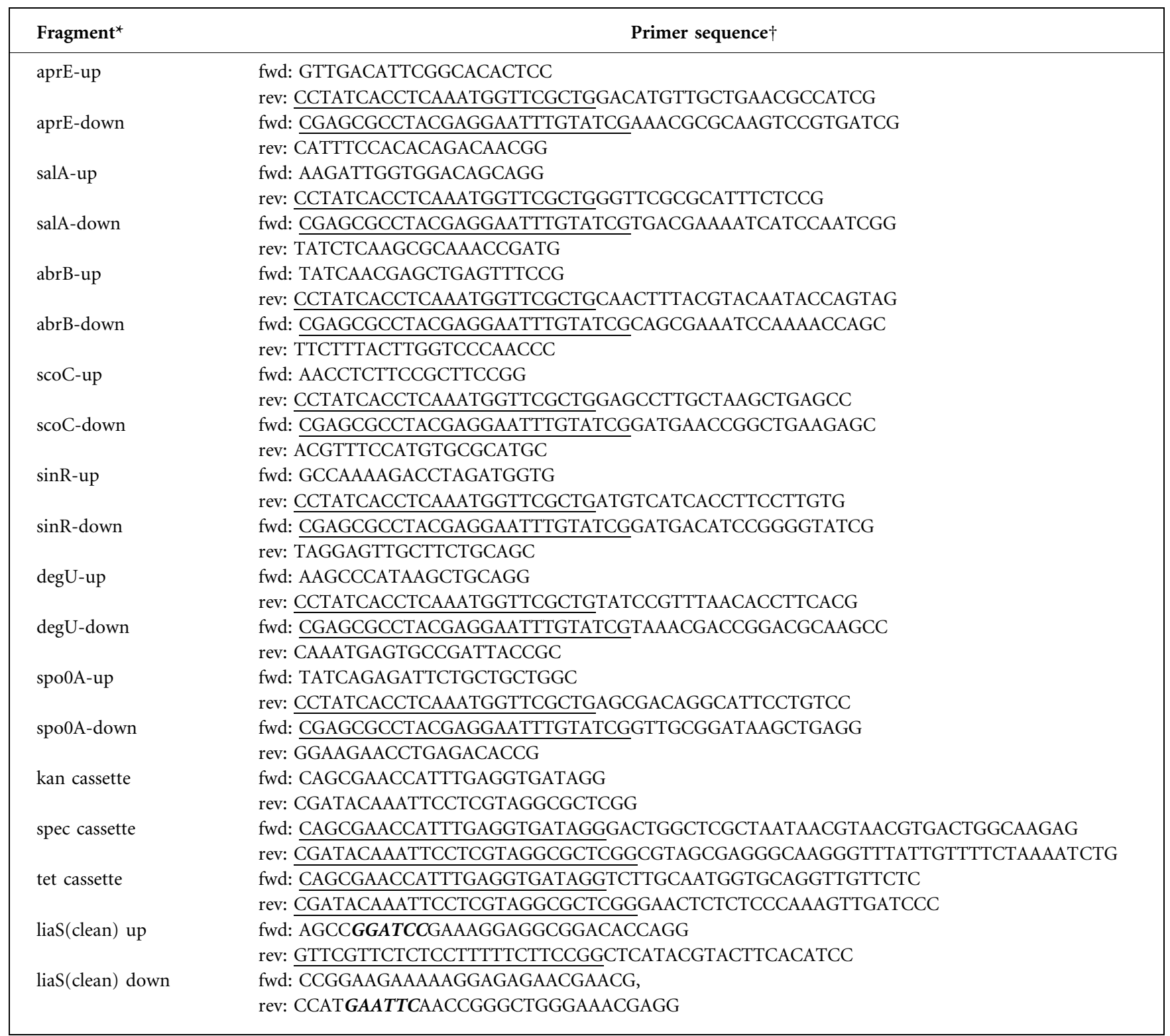

*'up' and 'down' refer to localization of the fragment relative to the gene(s) to be deleted. Both fragments are $\sim 1 \mathrm{~kb}$ in size and include $20-50$ nucleotides of the $5^{\prime}$ - or $3^{\prime}$-end of the corresponding gene(s), respectively.

$\dagger$ 'fwd', forward. 'rev', reverse. The (universal) linker sequences used for joining reactions are underlined. Restriction sites are in bold italics.

LiaH detection, $10 \mu \mathrm{l}$ CDP-Star chemiluminescence substrate (Roche Diagnostics) in $1 \mathrm{ml}$ buffer III was used. The signal was documented with a ChemiSmart LumiImager (peqlab).

DNase I footprinting assays. AbrB and Abh purification and DNase I footprinting assays were performed essentially as described previously (Bobay et al., 2006; Strauch et al., 1989). The DNA target was a $287 \mathrm{bp}$ fragment containing the liaI promoter region (positions -159 to +128$)$, end-labelled with ${ }^{32} \mathrm{P}$ on the template strand. The binding reactions were performed at $20{ }^{\circ} \mathrm{C}$ at $\mathrm{pH} 8$ for $\mathrm{AbrB}$, and $\mathrm{pH} 7$ for Abh (the optimal pHs for each protein's binding) (Bobay et al., 2006).

\section{RESULTS AND DISCUSSION}

\section{The lial promoter $\left(\mathbf{P}_{\text {lial }}\right)$ is induced without exogenous stimuli at the onset of stationary phase}

Induction of $\mathrm{P}_{\text {lial }}$ after addition of exogenous stimuli, such as cell-wall antibiotics, is well documented (Mascher et al., 2004; Pietiäinen et al., 2005). To investigate if $\mathrm{P}_{\text {liaI }}$ is also induced in their absence, we examined expression of a $\mathrm{P}_{\text {lial }}$ lacZ fusion in the reporter strain BFS2470. This strain 
harbours an insertion of the vector pMUTIN (Vagner et al., 1998) inside the liaI coding sequence, thereby bringing a promoterless lac $Z$ gene under control of the liaI promoter (Mascher et al., 2003, 2004).

To study $\mathrm{P}_{\text {liaI }}$ activity in the absence of external stimuli, BFS2470 was grown in LB medium with MLS selection over a period of $8 \mathrm{~h}$ and samples were taken every hour from mid-exponential to late-stationary growth phase. The cells were harvested and $\beta$-galactosidase activity was determined, essentially as described previously (Mascher et al., 2004). The results demonstrate that $\mathrm{P}_{\text {liaI }}$ is induced 8-10-fold without addition of cell-wall antibiotics during transition to stationary phase (Fig. 1a, grey bars). This induction is completely LiaR-dependent: no $\mathrm{P}_{\text {liaI }}$ activity was observed in the isogenic liaR mutant strain TMB011 (Fig. 1a, black bars).

These observations were verified independently by Western analysis in the wild-type and an isogenic liaR mutant (strain HB0933). Cells were harvested from both cultures at two time points, $2 \mathrm{~h}$ before and after transition state (equivalent to the 2 and $6 \mathrm{~h}$ time points in Fig. 1a). Total cellular protein was prepared and Western analysis performed with LiaH antibodies. The results are in agreement with the data from the $\beta$-galactosidase assays. LiaH expression is induced in stationary phase in the wildtype, but not in the liaR mutant (inset to Fig. 1a). Furthermore, induction of liaIH expression was also observed at the transcript level in a wild-type $B$. subtilis strain during a chronotranscriptome analysis (see below). While only results from $\beta$-galactosidase assays will be shown for subsequent experiments, all key findings were always independently verified by Western analysis.

Transition state adaptation, which enables B. subtilis to gradually adjust to nutrient limitations, is embedded in one of the best-studied bacterial developmental programmes, a complex regulatory cascade that ultimately leads to the formation of highly resistant endospores (Errington, 2003; Msadek, 1999; Phillips \& Strauch, 2002). It is well known that sporulation (and other transition-state phenomena such as production of extracellular enzymes, motility and biofilm formation) is subject to carbon catabolite repression (Schaeffer et al., 1965; Shafikhani et al., 2003; Stanley et al., 2003): cells grown with high amounts of glucose enter stationary phase without activating the gene expression cascade associated with sporulation. Therefore, we repeated the experiment shown in Fig. 1 in the presence of increasing glucose concentrations. Addition of glucose to the medium delayed $(0.1 \%$ glucose, grey bars $)$ or even abolished $(0.5 \%$ glucose, white bars $) \mathrm{P}_{\text {lial }}$ induction, without affecting overall growth rate, onset of stationary phase or final cell density (Fig. 1b). High glucose concentrations repress the activation of Spo0A, a key regulator of numerous post-exponential processes including sporulation. The activation of Spo0A results in two major effects on gene expression. First, it leads to the activation of a cascade of sigma factors that ultimately (a)

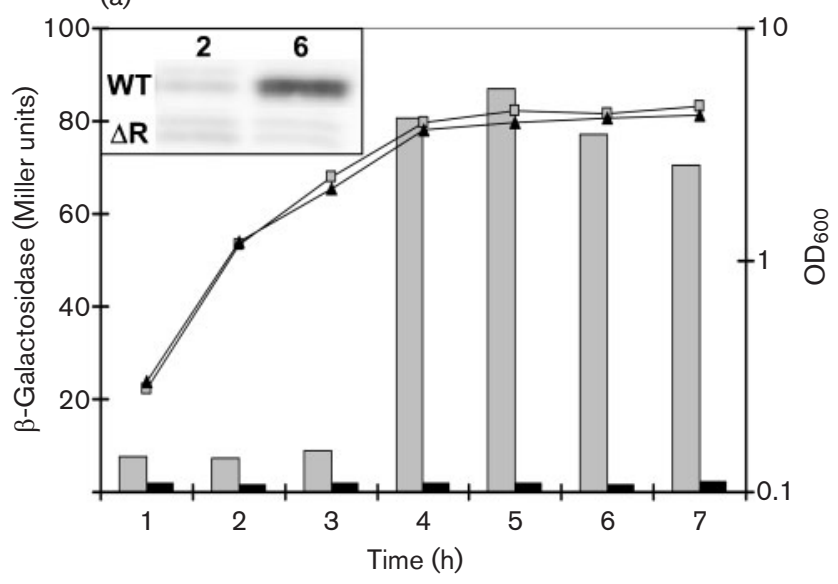

(b)

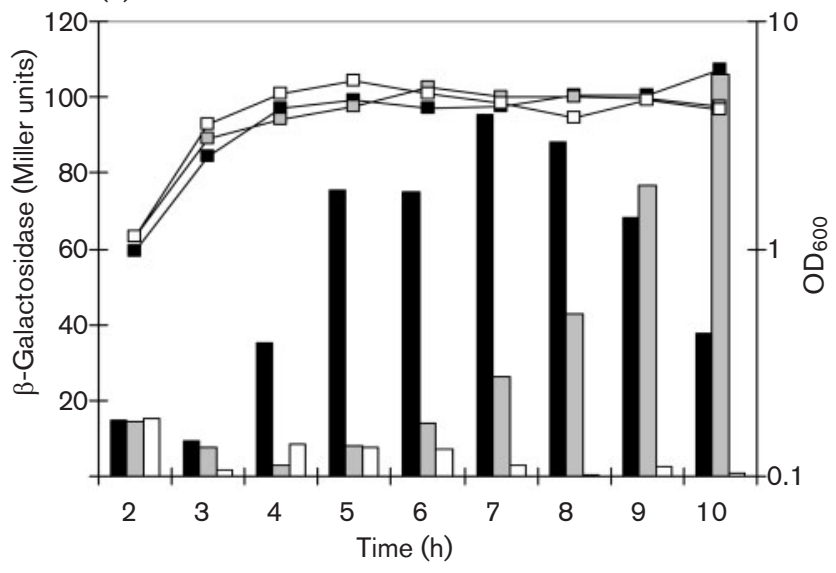

Fig. 1. Transition state induction of $\mathrm{P}_{\text {lial. }}$ (a) LB medium (20 ml, with MLS selection) was inoculated from a fresh mid-exponential preculture of strains BFS2470 ('wild-type', grey squares and grey bars) and TMB011 (liaR mutant, black triangles and black bars) and incubated at $37{ }^{\circ} \mathrm{C}$ with aeration. Cell density was monitored by measuring $\mathrm{OD}_{600}$ at regular intervals, and samples were taken every hour from mid-exponential until late stationary growth phase. The cells were harvested and lysed and a $\beta$-galactosidase assay was performed as described previously (Mascher et al., 2004). $\beta$ Galactosidase activity, normalized to cell density, is expressed in Miller units (Miller, 1972). The timescale is given relative to the start of the cultures. The inset shows results of a Western blot analysis of $\mathrm{LiaH}$ expression. Samples $(20 \mu \mathrm{g})$ of total proteins of the wild-type (W168) and an isogenic liaR mutant (HB0933; $\Delta \mathrm{R})$ were separated by SDS-PAGE. Western blots were performed using CDP-Star (Roche) for chemiluminescent detection, according to the manufacturer's instructions. See Methods for details. (b) The same experiment as in (a) was performed. Only the wild-type reporter strain BFS2470 was used. The preculture was used to inoculate three different flasks containing $20 \mathrm{ml}$ LB each, without (black symbols/ bars), and with the addition of glucose to a final concentration of $0.1 \%$ (grey symbols/bars) or $0.5 \%$ (white symbols/bars).

govern the formation of the dormant endospore. Second, Spo0A P represses $\mathrm{AbrB}$, which itself is a repressor of numerous genes associated with antibiotic production and 
resistance (Errington, 2003; Msadek, 1999; Phillips \& Strauch, 2002). While addition of glucose has pleiotropic effects on numerous regulatory pathways, this observation can nevertheless be viewed as an indication of a link between LiaRS-dependent gene expression and transitionstate regulation.

A second line of evidence pointing in this direction came from results obtained in a detailed chronotranscriptome study, in which the global gene expression pattern was monitored during a complete growth curve with a resolution of 10 min (Sapolsky et al., 2005). This study not only verified the transition-state induction of liaIH (but not liaGFSR) in a $B$. subtilis wild-type strain at the transcript level, but also revealed that expression of liaIH coincides with that of only one other gene, aprE (Eugenio Ferrari, personal communication). This observation can be interpreted in two ways: either $\mathrm{P}_{\text {liaI }}$ is induced as a result of aprE expression, or both loci are subject to the same regulation.

\section{$P_{\text {lial }}$ is repressed by AbrB and activated by Spo0A}

To address the first hypothesis, an aprE mutant was constructed by LFH-PCR, and introduced into the $\mathrm{P}_{\text {liaI }}$ reporter strain, resulting in strain TMB085 (Table 1). No difference of $\mathrm{P}_{\text {liaI }}$ activity was observed relative to the wildtype reporter strain BFS2470 (data not shown). Therefore, AprE is not involved in $\mathrm{P}_{\text {liaI }}$ induction.

The aprE promoter is subject to complex regulation: one activator (DegU) and three repressors (ScoC, SinR and AbrB) bind directly to the aprE promoter region. The activity of these proteins is modulated by additional proteins, such as Spo0A, SalA and RapG/PhrG (Ogura et al., 2003, 2004). To analyse a potential role of these proteins in $\mathrm{P}_{\text {liaI }}$ activity, mutants in $a b r B, s c o C$, sinR and $\operatorname{deg} U$ were constructed and subsequently transferred into the $\mathrm{P}_{\text {liaI }}$ reporter strain BFS2470 (Table 1). No alterations of $\mathrm{P}_{\text {liaI }}$ activity were observed in the $\operatorname{sco}$, $\sin R$ and $\operatorname{deg} U$ mutant backgrounds (data not shown). In contrast, the $a b r B$ mutation in strain TMB087 resulted in an about fourfold elevated basal expression level during the exponential growth phase, indicating that $\mathrm{AbrB}$ acts as a repressor at $\mathrm{P}_{\text {liaI }}$ during that time (Fig. 2, black bars). The promoter is still inducible to about wild-type levels. Both the basal promoter activity and the induction of $\mathrm{P}_{\text {liaI }}$ in the $a b r B$ mutant are completely dependent on LiaS-mediated activation of its cognate response regulator, LiaR: a liaS/ abrB mutant (TMB330; harbouring a clean liaS deletion to avoid polar effects on liaR expression) behaves similarly to a liaR mutant, i.e. does not show any $\mathrm{P}_{\text {liaI }}$ activity throughout the growth curve (data not shown).

A close regulatory connection between the transition state regulator $\mathrm{AbrB}$ and $\mathrm{Spo} 0 \mathrm{~A}$, the master regulator of sporulation, is well established: AbrB inhibits Spo0A expression indirectly via $\sigma^{\mathrm{H}}$, contributing to the mechanisms governing temporal control of sporulation initiation.

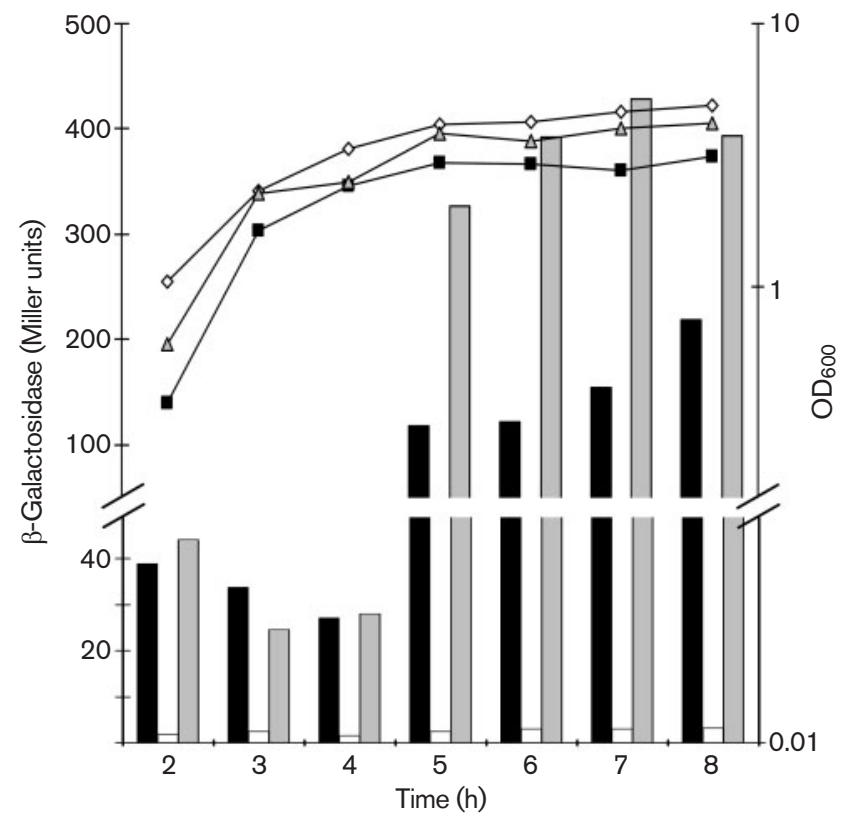

Fig. 2. Effect of $a b r B$ and $s p o O A$ mutations on $\mathrm{P}_{\text {lial }}$ activity. Growth and $\beta$-galactosidase activity of $\mathrm{P}_{\text {lial }}$-lac $Z$ fusions were measured for an $a b r B$ (TMB087, black squares and black bars), a spoOA (TMB118, white diamonds and white bars), and an abrB/ spoOA mutant (TMB209, grey triangles and grey bars), respectively. The experiment was performed as described in the legend to Fig. 1(a). The scale on the $y$-axis is split for clarity.

Activated Spo0A, on the other hand, represses $a b r B$ expression, ultimately releasing transition state functions, and $\sigma^{\mathrm{H}}$ expression, from $\mathrm{AbrB}$ repression at the onset of stationary phase (Msadek, 1999; Phillips \& Strauch, 2002). As a consequence, mutations in the two genes usually exhibit converse phenotypes on genes subject to their regulation. This could also be observed for $\mathrm{P}_{\text {liaI }}$ activity: a spo0A mutant (TMB118, Table 1) behaved very similarly to the liaR mutant in the $\beta$-galactosidase assay, i.e. had no detectable $\mathrm{P}_{\text {liaI }}$ activity (Fig. 2, white bars). These findings were also verified by Western analysis (data not shown). They are in agreement with results from previous transcriptome studies, indicating an indirect Spo0Adependent induction of liaIH expression (Fawcett et al., 2000; Fujita et al., 2005; Hamon et al., 2004). Therefore, $\mathrm{P}_{\text {lial }}$ is subject to $\mathrm{AbrB}$ repression and Spo0A activation.

\section{Spo0A activates $\mathbf{P}_{\text {lial }}$ indirectly through AbrB}

The loss of transition-state induction of $\mathrm{P}_{\text {liaI }}$ in the spo0A mutant raised the question of how Spo0A affects its promoter activity. The $a b r B$ gene is known to be under the direct negative control of Spo0A, and $\mathrm{AbrB}$ acts as a repressor of a set of genes that are switched on at the transition state (Strauch et al., 1990, 1989). Therefore, Spo0A activation of $\mathrm{P}_{\text {liaI }}$ could be an indirect effect due to the lack of Spo0A-dependent repression of abrB. 
Alternatively, Spo0A itself could be responsible for the expression of genes that ultimately provide the stimulus that is sensed by the LiaRS TCS at the onset of stationary phase. To distinguish between the two possibilities, a mutant lacking both $a b r B$ and $s p o 0 A$ was constructed and introduced into BFS2470, resulting in strain TMB209. This mutant showed a $\mathrm{P}_{\text {liaI }}$ induction pattern comparable to the $a b r B$ mutant, i.e. an elevated basal level of $\mathrm{P}_{\text {liaI }}$ activity during exponential growth, and induction at the onset of stationary phase (Fig. 2). Interestingly, the maximum $\mathrm{P}_{\text {liaI }}$ activity was reproducibly higher by a factor of two than in the $a b r B$ mutant (Fig. 2, grey bars). The reason for this behaviour remains elusive. However, the results clearly demonstrate that Spo0A indirectly modulates $\mathrm{P}_{\text {liaI }}$ activity by repressing $a b r B$ expression.

\section{AbrB directly binds $\mathbf{P}_{\text {lial }}$}

The transition-state regulator $\mathrm{AbrB}$ directly regulates (mostly represses) the expression of over 50 genes, with many additional loci being subject to indirect $\mathrm{AbrB}$ control (Phillips \& Strauch, 2002). Despite in-depth knowledge on numerous AbrB binding sites, no consensus sequence has been identified for chromosomal sites of interaction. It has

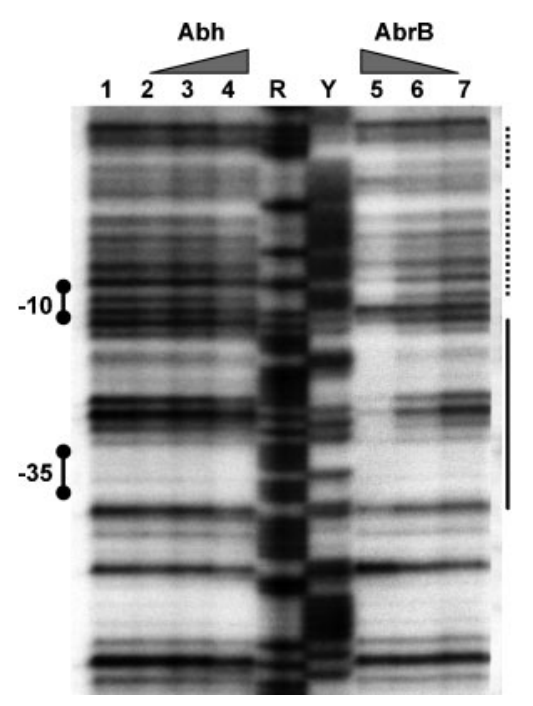

Fig. 3. DNase $\mid$ footprinting analysis of $A b r B$ binding to $P_{\text {lial. }}$. DNase I footprinting was performed as described previously (Bobay et al., 2006; Strauch et al., 1989). Lanes 1, 2, 7, no protein; 3, $6 \mu \mathrm{M}$ Abh; 4, $20 \mu \mathrm{M}$ Abh; 5, $20 \mu \mathrm{M}$ AbrB; 6, $6 \mu \mathrm{M}$ AbrB. AbrB binding reactions were performed at $\mathrm{pH} 8$; Abh binding at $\mathrm{pH} 7$ (the optimal $\mathrm{pHs}$ for each protein's binding; Bobay et al., 2006). R, Y, Maxam-Gilbert purine and pyrimidine chemical sequencing reactions. The DNA target was a $287 \mathrm{bp}$ fragment containing the lial promoter region (positions -159 to +128 ) endlabelled on the template strand. Solid vertical line on right, seemingly stronger AbrB binding region; dashed lines on right, seemingly weaker protection region due to AbrB binding. -35 and -10 regions of the lial promoter are indicated on the left. been hypothesized that $\mathrm{AbrB}$ recognizes a conserved threedimensional DNA structure, rather than specific base pairs, in the promoter regions of its target genes (Bobay et al., 2004; Phillips \& Strauch, 2002; Xu \& Strauch, 1996). DNase I footprinting analysis of the liaI promoter region demonstrates that $\mathrm{AbrB}$ protects a DNA region of about 25 base pairs (from -40 to -14 ), with weaker protection occurring further downstream (from -11 to about +10 ) (Fig. 3). In contrast, the AbrB paralogue Abh does not bind the $\mathrm{P}_{\text {liaI }}$ region under these conditions (Fig. 3). We conclude that $\mathrm{AbrB}$ repression of $\mathrm{P}_{\text {liaI }}$ occurs through direct binding of the repressor within the promoter sequence, thereby preventing transcription initiation.

\section{LiaR is sufficient for $\mathbf{P}_{\text {lial }}$ induction}

Induction of $\mathrm{P}_{\text {liaI }}$ under conditions of cell envelope stress is strictly LiaR-dependent (Mascher et al., 2003). To determine if $\mathrm{AbrB}$ or Spo0A are also necessary for $\mathrm{P}_{\text {liar }}$ dependent transcription in the presence of external stimuli, such as bacitracin, we performed $\beta$-galactosidase assay and Western analysis in the wild-type, and isogenic liaR, abrB and spo0A mutants from cells harvested mid-exponentially with and without the presence of bacitracin (final concentration $50 \mu \mathrm{g} \mathrm{ml}^{-1}$ ). With the exception of the liaR mutant, all strains were inducible to comparable levels, demonstrating that LiaR alone is sufficient for bacitracininduced $\mathrm{P}_{\text {liaI }}$ activity (Fig. 4, and data not shown). These experiments also demonstrate that strong inducers such as bacitracin (3000-4000 Miller units from $\mathrm{P}_{\text {lia }}$ lac $Z$ in

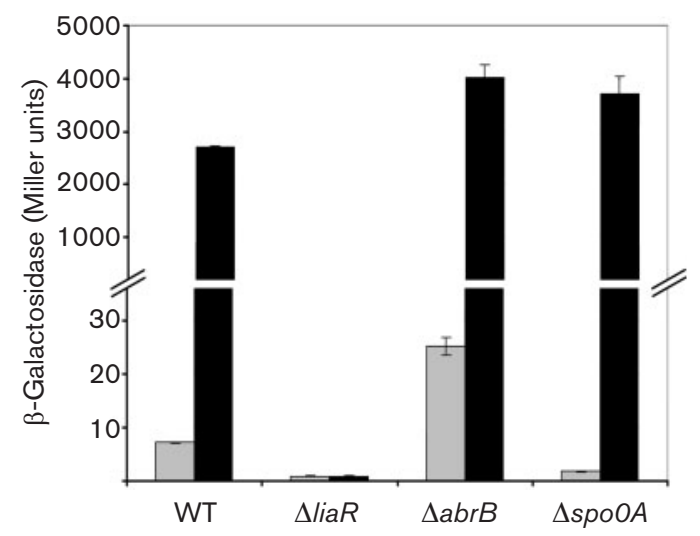

Fig. 4. Bacitracin induction of $P_{\text {lial }}$ in BFS2470 (WT), and isogenic liaR (TMB011), abrB (TMB087), and spoOA (TMB118) mutants. All strains were grown in LB medium with MLS selection to mid-exponential phase. The cultures were split; half were induced with bacitracin (final concentration $50 \mu \mathrm{g} \mathrm{ml}^{-1}$; black bars), the other half remained as uninduced controls (grey bars). Incubation was continued for $30 \mathrm{~min}$, before $2 \mathrm{ml}$ of culture was harvested. The cells were lysed and the $\beta$-galactosidase assay was performed as described previously (Mascher et al., 2004). $\beta$ Galactosidase activity, normalized to cell density, is expressed in Miller units (Miller, 1972). The scale on the $y$-axis is split for clarity. 
$\beta$-galactosidase assays) can completely overcome $\mathrm{AbrB}$ repression, whereas the endogenous transition state induction (100-200 Miller units) can be suppressed by increased cellular levels of $\mathrm{AbrB}$ as present in the spo0A mutant. The mechanism by which fully activated LiaR (i.e. in response to bacitracin stress) seemingly 'overrides' AbrB control is completely unknown. We can only speculate that the affinity of phosphorylated LiaR for its target promoter somehow is higher than that of $\mathrm{AbrB}$, whereby activated LiaR seems to be able to displace bound AbrB and initiate $\mathrm{P}_{\text {liar }}$-dependent transcription in the presence of strong inducers.

\section{The nature of the endogenous stimulus responsible for transition state induction of $P_{\text {lial }}$ remains obscure}

The known induction of $\mathrm{P}_{\text {liaI }}$ by cell-wall antibiotics led us to hypothesize that induction in early stationary phase might be due to a secreted antibiotic synthesized by $B$. subtilis itself (Stein, 2005). To address this question, induction experiments with spent medium were performed. The wild-type reporter strain BFS2470 was grown in LB medium with MLS selection until $2 \mathrm{~h}$ after transition state (corresponding to $t=6 \mathrm{~h}$ in Fig. 1a). A sample of the culture was harvested to check for $\mathrm{P}_{\text {liaI }}$ induction. The cells were removed from the remaining culture and the spent medium was directly used to resuspend fresh mid-exponential cells $(t=2 \mathrm{~h})$ that were incubated in parallel. Additionally, cells were resuspended in fresh prewarmed LB medium, with and without addition of bacitracin (final concentration $50 \mu \mathrm{g} \mathrm{ml}^{-1}$ ), as a positive and negative control, respectively. After further incubation at $37{ }^{\circ} \mathrm{C}$ for $30 \mathrm{~min}$, the cells were harvested. The cells from the stationary-phase culture showed the expected $\beta$ galactosidase activity ( $\sim 150$ Miller units). Resuspension of mid-exponential phase cells in fresh LB medium only resulted in the normal background activity of about 10 Miller units, while resuspension in LB medium supplemented with bacitracin gave the typical strong $\mathrm{P}_{\text {liaI }}$ response (about 2000 Miller units). In contrast, no induction was observed when mid-exponential cells were resuspended in spent medium (data not shown). These results indicate that $\mathrm{P}_{\text {liaI }}$ is not induced by a secreted compound produced by $B$. subtilis itself.

However, we cannot rule out the possibility that the inducing antibiotic is not released from the cells in sufficient amounts in the medium to be detectable in our conditioned-medium experiments. For example, a prerequisite for the biological potency of many cationic antimicrobial peptides is their binding to the overall negatively charged cell envelope, and modulating this net charge is an important resistance mechanism of many Gram-positive bacteria against their activity (Kovács et al., 2006; Peschel et al., 1999). Conversely, one could imagine that such an antibiotic, produced by B. subtilis itself, might be retained to a certain degree by the negatively charged cell wall. Therefore, while $\mathrm{P}_{\text {liaI }}$ induction could then be readily measured in the antibiotic-producing stationary phase culture, this inducer would not necessarily accumulate in the medium in amounts sufficient to activate $\mathrm{P}_{\text {liaI }}$ in resuspended mid-exponential phase cells.

We also attempted to identify potential genetic determinants involved in generating the endogenous stimulus by applying transposon mutagenesis in the $\mathrm{P}_{\text {liar }}$ lacZ reporter strain BFS2470 and screening for blue colonies, indicative of increased $\mathrm{P}_{\text {lial }}$ activity. Two independent approaches were used, in vivo transposon mutagenesis, based on the established mini-Tn10 system encoded on plasmid pIC333 (Steinmetz \& Richter, 1994), and a newly developed in vitro system, based on Tn7 (Peters \& Craig, 2001). The latter also allows gain-of-function mutagenesis screens, due to the presence of an outward-facing, xylose-inducible promoter. We readily isolated mutants with transposon insertions in liaF, the known negative regulator of the LiaRS systems (Jordan et al., 2006). In addition, we recovered insertions in the export pump of a putative bacteriocin, indicating that endogenous peptides produced by $B$. subtilis can induce the LiaRS system (Butcher and Helmann, unpublished). However, strains lacking the ability to produce this bacteriocin still induce $\mathrm{P}_{\text {liaI }}$ upon entry into stationary phase (data not shown). Therefore, the nature of this endogenous stimulus remains unknown.

\section{Conclusions}

Based on the results of previous studies and those presented herein, the intrinsic induction of liaIH expression at the onset of stationary phase is tightly regulated and delicately balanced by five proteins - LiaR, LiaS, LiaF, AbrB and SpoOA - to allow an appropriate cellular response at the right time. The interactions and hierarchy of these regulators is illustrated in the model in Fig. 5. During exponential growth in the absence of cell-envelope stress, the LiaRS two-component system is kept inactive by the LiaF regulator (Jordan et al., 2006). Furthermore, the transition-state regulator $\mathrm{AbrB}$ represses any residual $\mathrm{P}_{\text {liaI }}$ activity by binding to a DNA fragment that includes the -35 region and reaches the -10 region, thereby serving as a roadblock that efficiently prevents transcription initiation (Fig. 5, right-hand side). At the onset of stationary phase, increasing levels of phosphorylated Spo0A, the master regulator of sporulation, inhibit $a b r B$ expression (Strauch et al., 1990), thereby releasing $\mathrm{P}_{\text {liaI }}$ from its repression. At about the same time, an unidentified stimulus leads to the activation of the histidine kinase LiaS and/or its release from LiaF repression. This, in turn, leads to the activation of the cognate response regulator LiaR, which interacts with its binding site (an imperfect inverted repeat of seven nucleotides with four-nucleotide spacing) (Jordan et al., 2006), ultimately resulting in induction of liaIH expression (Fig. 5, left-hand side).

Previous studies identified numerous agents that are able to induce LiaRS-dependent gene expression. While some of these compounds, especially cell-wall antibiotics that 


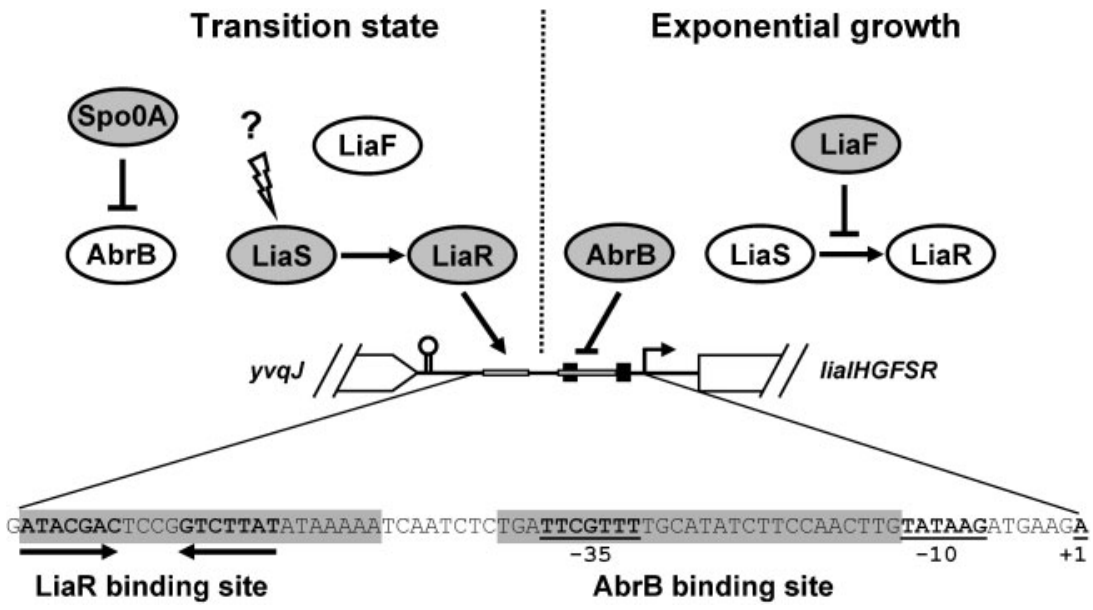

Fig. 5. Model for the transition state regulation of $\mathrm{P}_{\text {lial }}$ activity. The situations during exponential growth and the transition state are shown on the right and left, respectively. Regulatory proteins involved are named and circled. Grey backgrounds indicate activity, white inactivity. Arrows indicate activation, T-shaped lines repression. The genomic context of the lial promoter region and its important features are shown schematically in the middle; the relevant sequence is detailed below. The identified regulator binding sites are highlighted in grey. The inverted repeat in the LiaR binding site is indicated by the two arrows below. The promoter sequence and transcriptional start are highlighted in bold and underlined. See text for details.

interfere with the lipid II cycle (i.e. bacitracin, nisin, ramoplanin or vancomycin), elicit a strong response (Mascher et al., 2004), the biological relevance of these observations remains obscure, since the LiaRS system is not involved in mediating resistance against any of these inducers (unpublished results). The induction of $\mathrm{P}_{\text {liaI }}$ at the onset of stationary phase - while being significantly weaker [about 10-15-fold, Fig. 1a, compared to 50-200-fold in the case of strong inducers (Mascher et al., 2004), Fig. 4] - is therefore an important observation. While a very high dynamic potential and strength of LiaRS-dependent gene expression could be demonstrated by the exogenous addition of cell-wall antibiotics (Mascher et al., 2004), this situation does not necessarily reflect the 'natural' condition for the activation of LiaRS-dependent signal transduction. The different sites and modes of action of these known inducers of the LiaRS system, together with the unique domain architecture of the sensor kinase LiaS, argue against a direct binding of these drugs to the input domain of LiaS (Mascher, 2006). Identification of the true sensory input of the LiaRS system, while being a big challenge, is therefore a prerequisite to understanding the difference in LiaR-dependent gene expression observed in this study.

\section{ACKNOWLEDGEMENTS}

We thank Eugenio Ferrari (Genencor) for sharing unpublished results from their chronotranscriptome study, Zoltan Pragai for the gift of strain BFS2470, and Jörg Stülke, in whose laboratory this research was conducted. This work was financially supported by grants GM46700 (to M.A.S.) and GM47446 (to J.D. H.) from the National Institutes of Health, and grants from the Deutsche Forschungsgemeinschaft (MA3269) and the Fonds der Chemischen Industrie (to T. M.).

\section{REFERENCES}

Adams, H., Teertstra, W., Demmers, J., Boesten, R. \& Tommassen, J. (2003). Interactions between phage-shock proteins in Escherichia coli. J Bacteriol 185, 1174-1180.
Arnaud, M., Chastanet, A. \& Debarbouille, M. (2004). New vector for efficient allelic replacement in naturally nontransformable, low-GCcontent, Gram-positive bacteria. Appl Environ Microbiol 70, 6887-6891.

Bobay, B. G., Benson, L., Naylor, S., Feeney, B., Clark, A. C., Goshe, M. B., Strauch, M. A., Thompson, R. \& Cavanagh, J. (2004). Evaluation of the DNA binding tendencies of the transition state regulator AbrB. Biochemistry 43, 16106-16118.

Bobay, B. G., Mueller, G. A., Thompson, R. J., Murzin, A. G., Venters, R. A., Strauch, M. A. \& Cavanagh, J. (2006). NMR structure of AbhN and comparison with AbrBN: first insights into the DNA binding promiscuity and specificity of AbrB-like transition state regulator proteins. J Biol Chem 281, 21399-21409.

Bordes, P., Wigneshweraraj, S. R., Schumacher, J., Zhang, X., Chaney, M. \& Buck, M. (2003). The ATP hydrolyzing transcription activator phage shock protein $\mathrm{F}$ of Escherichia coli: identifying a surface that binds $\sigma^{54}$. Proc Natl Acad Sci U S A 100, 2278-2283.

Brissette, J. L., Russel, M., Weiner, L. \& Model, P. (1990). Phage shock protein, a stress protein of Escherichia coli. Proc Natl Acad Sci U S A 87, 862-866.

Darwin, A. J. (2005). The phage-shock-protein response. Mol Microbiol 57, 621-628.

Dworkin, J., Jovanovic, G. \& Model, P. (2000). The PspA protein of Escherichia coli is a negative regulator of $\sigma^{54}$-dependent transcription. J Bacteriol 182, 311-319.

Errington, J. (2003). Regulation of endospore formation in Bacillus subtilis. Nat Rev Microbiol 1, 117-126.

Fawcett, P., Eichenberger, P., Losick, R. \& Youngman, P. (2000). The transcriptional profile of early to middle sporulation in Bacillus subtilis. Proc Natl Acad Sci U S A 97, 8063-8068.

Fujita, M., Gonzalez-Pastor, J. E. \& Losick, R. (2005). High- and lowthreshold genes in the Spo0A regulon of Bacillus subtilis. J Bacteriol 187, 1357-1368.

Guerout-Fleury, A. M., Shazand, K., Frandsen, N. \& Stragier, P. (1995). Antibiotic-resistance cassettes for Bacillus subtilis. Gene 167, 335-336.

Haas, W., Kaushal, D., Sublett, J., Obert, C. \& Tuomanen, E. I. (2005). Vancomycin stress response in a sensitive and a tolerant strain of Streptococcus pneumoniae. J Bacteriol 187, 8205-8210.

Hamon, M. A., Stanley, N. R., Britton, R. A., Grossman, A. D. \& Lazazzera, B. A. (2004). Identification of AbrB-regulated genes 
involved in biofilm formation by Bacillus subtilis. Mol Microbiol 52, 847-860.

Harwood, C. R. \& Cutting, S. M. (1990). Molecular Biological Methods for Bacillus. Chichester: Wiley.

Hyyryläinen, H. L., Sarvas, M. \& Kontinen, V. P. (2005). Transcriptome analysis of the secretion stress response of Bacillus subtilis. Appl Microbiol Biotechnol 67, 389-396.

Jordan, S., Junker, A., Helmann, J. D. \& Mascher, T. (2006). Regulation of LiaRS-dependent gene expression in Bacillus subtilis: identification of inhibitor proteins, regulator binding sites and target genes of a conserved cell envelope stress-sensing two-component system. J Bacteriol 188, 5153-5166.

Kleerebezem, M. \& Tommassen, J. (1993). Expression of the $p s p A$ gene stimulates efficient protein export in Escherichia coli. Mol Microbiol 7, 947-956.

Kleerebezem, M., Crielaard, W. \& Tommassen, J. (1996). Involvement of stress protein PspA (phage shock protein A) of Escherichia coli in maintenance of the protonmotive force under stress conditions. EMBO J 15, 162-171.

Kobayashi, H., Yamamoto, M. \& Aono, R. (1998). Appearance of a stress-response protein, phage-shock protein A, in Escherichia coli exposed to hydrophobic organic solvents. Microbiology 144, 353-359.

Kovács, M., Halfmann, A., Fedtke, I., Heintz, M., Peschel, A., Vollmer, W., Hakenbeck, R. \& Brückner, R. (2006). A functional dlt operon, encoding proteins required for incorporation of $\mathrm{D}$-alanine in teichoic acids in Gram-positive bacteria, confers resistance to cationic antimicrobial peptides in Streptococcus pneumoniae. J Bacteriol 188, 5797-5805.

Kuroda, M., Kuroda, H., Oshima, T., Takeuchi, F., Mori, H. \& Hiramatsu, K. (2003). Two-component system VraSR positively modulates the regulation of cell-wall biosynthesis pathway in Staphylococcus aureus. Mol Microbiol 49, 807-821.

Mascher, T. (2006). Intramembrane-sensing histidine kinases: a new family of cell envelope stress sensors in Firmicutes bacteria. FEMS Microbiol Lett 264, 133-144.

Mascher, T., Margulis, N. G., Wang, T., Ye, R. W. \& Helmann, J. D. (2003). Cell wall stress responses in Bacillus subtilis: the regulatory network of the bacitracin stimulon. Mol Microbiol 50, 1591-1604.

Mascher, T., Zimmer, S. L., Smith, T. A. \& Helmann, J. D. (2004). Antibiotic-inducible promoter regulated by the cell envelope stresssensing two-component system LiaRS of Bacillus subtilis. Antimicrob Agents Chemother 48, 2888-2896.

Miller, J. H. (1972). Experiments in Molecular Genetics. Cold Spring Harbor, NY: Cold Spring Harbor Laboratory.

Msadek, T. (1999). When the going gets tough: survival strategies and environmental signaling networks in Bacillus subtilis. Trends Microbiol 7, 201-207.

Ogura, M., Shimane, K., Asai, K., Ogasawara, N. \& Tanaka, T. (2003). Binding of response regulator DegU to the aprE promoter is inhibited by RapG, which is counteracted by extracellular PhrG in Bacillus subtilis. Mol Microbiol 49, 1685-1697.

Ogura, M., Matsuzawa, A., Yoshikawa, H. \& Tanaka, T. (2004). Bacillus subtilis SalA (YbaL) negatively regulates expression of scoC, which encodes the repressor for the alkaline exoprotease gene, aprE. $J$ Bacteriol 186, 3056-3064.

Peschel, A., Otto, M., Jack, R. W., Kalbacher, H., Jung, G. \& Götz, F. (1999). Inactivation of the dlt operon in Staphylococcus aureus confers sensitivity to defensins, protegrins, and other antimicrobial peptides. $J$ Biol Chem 274, 8405-8410.

Peters, J. E. \& Craig, N. L. (2001). Tn7: smarter than we thought. Nat Rev Mol Cell Biol 2, 806-814.
Petersohn, A., Brigulla, M., Haas, S., Hoheisel, J. D., Volker, U. \& Hecker, M. (2001). Global analysis of the general stress response of Bacillus subtilis. J Bacteriol 183, 5617-5631.

Phillips, Z. E. \& Strauch, M. A. (2002). Bacillus subtilis sporulation and stationary phase gene expression. Cell Mol Life Sci 59, 392-402.

Pietiäinen, M., Gardemeister, M., Mecklin, M., Leskela, S., Sarvas, M. \& Kontinen, V. P. (2005). Cationic antimicrobial peptides elicit a complex stress response in Bacillus subtilis that involves ECF-type sigma factors and two-component signal transduction systems. Microbiology 151, 1577-1592.

Sambrook, J. \& Russell, D. W. (2001). Molecular Cloning - a Laboratory Manual. Cold Spring Harbor, NY: Cold Spring Harbor Laboratory.

Sapolsky, R., Iyer, P., Caldwell, B., Weyler, W., Chotani, G. \& Ferrari, E. (2005). Bacillus subtilis "Chronotranscriptomics": twenty-six timepoints of transcript profiling from mid-exponential to post-transition phase. In Abstracts of 3rd Conference on Functional Genomics of Gram-Positive Micro-organisms, June 12-16 2005, San Diego, California, abstract T18.

Schaeffer, P., Millet, J. \& Aubert, J. P. (1965). Catabolic repression of bacterial sporulation. Proc Natl Acad Sci U S A 54, 704-711.

Shafikhani, S. H., Partovi, A. A. \& Leighton, T. (2003). Cataboliteinduced repression of sporulation in Bacillus subtilis. Curr Microbiol 47, 300-308.

Silver, L. L. (2003). Novel inhibitors of bacterial cell wall synthesis. Curr Opin Microbiol 6, 431-438.

Silver, L. L. (2006). Does the cell wall of bacteria remain a viable source of targets for novel antibiotics? Biochem Pharmacol 71, 9961005.

Stanley, N. R., Britton, R. A., Grossman, A. D. \& Lazazzera, B. A. (2003). Identification of catabolite repression as a physiological regulator of biofilm formation by Bacillus subtilis by use of DNA microarrays. J Bacteriol 185, 1951-1957.

Stein, T. (2005). Bacillus subtilis antibiotics: structures, syntheses and specific functions. Mol Microbiol 56, 845-857.

Steinmetz, M. \& Richter, R. (1994). Easy cloning of mini-Tn10 insertions from the Bacillus subtilis chromosome. J Bacteriol 176, 1761-1763.

Strauch, M. A., Spiegelman, G. B., Perego, M., Johnson, W. C., Burbulys, D. \& Hoch, J. A. (1989). The transition state transcription regulator abrB of Bacillus subtilis is a DNA binding protein. EMBO J 8, 1615-1621.

Strauch, M., Webb, V., Spiegelman, G. \& Hoch, J. A. (1990). The Spo0A protein of Bacillus subtilis is a repressor of the abrB gene. Proc Natl Acad Sci U S A 87, 1801-1805.

Szurmant, H., Mohan, M. A., Imus, P. M. \& Hoch, J. A. (2007). YycH and YycI interact to regulate the essential YycFG two-component system in Bacillus subtilis. J Bacteriol 189, 3280-3289.

Tam le, T., Eymann, C., Albrecht, D., Sietmann, R., Schauer, F., Hecker, M. \& Antelmann, H. (2006). Differential gene expression in response to phenol and catechol reveals different metabolic activities for the degradation of aromatic compounds in Bacillus subtilis. Environ Microbiol 8, 1408-1427.

Vagner, V., Dervyn, E. \& Ehrlich, S. D. (1998). A vector for systematic gene inactivation in Bacillus subtilis. Microbiology 144, 3097-3104.

Wach, A. (1996). PCR-synthesis of marker cassettes with long flanking homology regions for gene disruptions in S. cerevisiae. Yeast 12, 259-265.

Walsh, C. (2003). Antibiotics - Actions, Origins, Resistance. Washington, DC: American Society for Microbiology. 
Wecke, T., Veith, B., Ehrenreich, A. \& Mascher, T. (2006). Cell envelope stress response in Bacillus licheniformis: integrating comparative genomics, transcriptional profiling, and regulon mining to decipher a complex regulatory network. J Bacteriol 188, 7500-7511.

Weiner, L. \& Model, P. (1994). Role of an Escherichia coli stressresponse operon in stationary-phase survival. Proc Natl Acad Sci U S A 91, 2191-2195.

Wiegert, T., Homuth, G., Versteeg, S. \& Schumann, W. (2001). Alkaline shock induces the Bacillus subtilis $\sigma^{\mathrm{W}}$ regulon. Mol Microbiol 41, 59-71.
Xu, K. \& Strauch, M. A. (1996). In vitro selection of optimal AbrBbinding sites: comparison to known in vivo sites indicates flexibility in $\mathrm{AbrB}$ binding and recognition of three-dimensional DNA structures. Mol Microbiol 19, 145-158.

Youngman, P. (1990). Use of transposons and integrational vectors for mutagenesis and construction of gene fusions in Bacillus subtilis. In Molecular Biological Methods for Bacillus, pp. 221-266. Edited by C. R. Harwood \& S. M. Cutting. Chichester: Wiley.

Edited by: M. Hecker 